\title{
Internal Control, Double Agency Costs and Corporate Social Responsibility
}

\author{
Junbao Yang \\ School of Business, Nanjing Normal University, Nanjing, China \\ Email: yangjb0108@163.com
}

How to cite this paper: Yang, J.B. (2019) Internal Control, Double Agency Costs and Corporate Social Responsibility. Open Journal of Social Sciences, 7, 155-167. https://doi.org/10.4236/jss.2019.79012

Received: June 25, 2019

Accepted: September 17, 2019

Published: September 20, 2019

Copyright $\odot 2019$ by author(s) and Scientific Research Publishing Inc. This work is licensed under the Creative Commons Attribution International License (CC BY 4.0).

http://creativecommons.org/licenses/by/4.0/

\begin{abstract}
With the development of economy, corporate social responsibility has been paid more and more attention. This paper examines the relationship between internal control and corporate social responsibility, and examines whether double agency costs act as intermediary roles. The research results show that effective internal control can improve the performance of corporate social responsibility and reduce the double agency costs. The first type of agency cost plays a part of intermediary role in the relationship between internal control and corporate social responsibility, while the second type of agency cost has no intermediary role.
\end{abstract}

\section{Keywords}

Internal Control, Corporate Social Responsibility, Double Agency Costs, Mediating Effect, Corporate Governance

\section{Introduction}

Since the 21st century, China's economy has experienced rapid growth, but various social problems have also erupted. "Sanlu milk powder", "ShenZhen Foxconn employee suicides", "the Changsheng vaccine" and the recent chemical plant explosion incident in XiangShui county are microcosm of China's frequent incidents of corporate social responsibility. Environmental pollution, production accidents, food safety and employee exploitation show that some enterprises in China have serious defects in social responsibility. At the same time, some enterprises are doing well in social responsibility: Cosco group, through its internal charity foundation, has made generous donations and actively rescued in the snow disaster in south China and Wenchuan Earthquake. It has continuously devoted itself to social welfare and designated assistance to backward areas and has been awarded commendations and awards by the Chinese ministry of civil 
affairs for many times. Its charity foundation also has been rated as a $4 \mathrm{~A}$ social organization by the Chinese ministry of civil affairs. What factors lead to such a huge gap in corporate social responsibility? Studies have shown that many factors, such as external environment, internal governance and senior executives' values, have an impact on corporate social responsibility. Internal control, as the key and basic system of modern enterprise governance, infiltrates into all aspects of the enterprise, which is bound to have an important impact on the implementation of corporate social responsibility. In addition, the separation of the two rights is a common feature of modern enterprises. The principal-agent problem is getting more and more attention, and its impact on corporate social responsibility cannot be ignored.

Most of the existing researches are based on internal control or agency costs alone, and examine the relationship between it and corporate social responsibility. In fact, many studies have proved that internal control, corporate social responsibility and agency cost are related to each other. Internal control plays an active role in reducing agency costs and improving corporate social responsibility performance. There are few studies that include the three in the same analytical framework. This leads to the effective path of internal control to corporate social responsibility which has not been fully explored. Besides, there is an obvious phenomenon of equity concentration in Chinese companies and the incidents of major shareholders abusing their power to extract illegal interests from minority shareholders occur frequently. The relationship between the second type of agency problem (major shareholders and minority shareholders) and internal control and corporate social responsibility is also worth exploring. Therefore, based on the existing research and empirical conclusion, this paper analyzes the relationship and mechanism between internal control, dual agency cost and corporate social responsibility, which deepens the understanding of the effective path of internal control. According to the empirical conclusions, this paper puts forward relevant suggestions for the development of internal control and the fulfillment of corporate social responsibility in China.

\section{Literature Review and Theoretical Hypothesis}

\subsection{Internal Control and Corporate Social Responsibility}

According to the traditional theory, shareholder profit or corporate profit maximization is the sole responsibility of an enterprise. However, with the continuous development of economy and theory, more and more scholars believe that the corporate responsibility is more than that. Davis (1960) proposed the "iron law of responsibility" [1]: an enterprise does not exist in a vacuum, but in social relations. The production and expansion of an enterprise cannot do without the support of other stakeholders in the society. When an enterprise enjoys its power, it should assume corresponding social responsibilities. Corporate Social Responsibility (CSR) was first formally proposed by British scholar Oliver Sheldon [2] in 1924. Subsequently, a large number of scholars conducted re- 
searches on its definition, motivation and consequences. Nowadays, CSR performance is not only the forced need of national economic and social development, but also the strategic choice of enterprise independent competition. Therefore, the influencing factors of CSR performance have become the focus of attention in recent years. Many studies have proved that the internal governance of enterprises will have a significant impact on the fulfillment of social responsibility. Internal control as the most concerned means of internal governance, its relationship with CSR has been extensively explored. High quality internal control and repair of internal control defects can significantly improve the performance of CSR and the level of social responsibility for different stakeholders is affected by internal control differently [3] [4]. In addition, the relationship between internal control and CSR is not a simple one-way action, but a two-way interaction, they promote each other [5]. Internal control promotes the fulfillment of CSR by improving business performance and strengthening CSR supervision [6]. Based on the perspective of spillover effect, Li (2014) empirically tested that internal control has a significant positive effect on the fulfillment of CSR, and this effect is stronger in state-owned controlled enterprises [7]. From the perspective of "meta-definition", Li and Xiao define corporate social responsibility as follows: under specific institutional arrangements, enterprises effectively manage the impact of their own operations on society, stakeholders and the natural environment, and seek to maximize social welfare within the expected duration [8]. Internal control, as the basis and focus of internal governance, is the supervision mechanism generated by enterprises in order to maximize the elimination of their own mistakes, use their own resources reasonably and guarantee the interests of stakeholders and social contributions in various systems. In 2010, the fifth ministry of the ministry of finance of China issued Corporate Internal Control Application Guidelines No. 4-Social Responsibility, which is used to guide internal control to ensure the fulfillment of corporate social responsibility. It puts "safe production, product quality, environmental protection and resource conservation, promotion of employment and protection of employees' rights and interests" into the internal control construction, and clearly regards internal control as a means to promote CSR. Therefore, hypothesis 1 is proposed in this paper.

H1: When other conditions are the same, good internal control can promote the implementation of CSR.

\subsection{Internal Control and Dual Agency Costs}

The separation of control and ownership is a typical feature of modern enterprises. This relationship conforms to the trend of modern enterprise development and also creates agency problems. Jensen and Meckling formally proposed the concept of agency cost in 1976 [9], analyzing the first type of agency problem between managers and shareholders. They believe that the agency cost consists of the monitoring expenditures by the principal, the agency's expense of signing 
the contract activity, and the remaining loss. They believe that the agency cost consists of the principal's supervision activity expenditure, the bonding expenditures by the agent and the residual loss. La Porta et al. analyzed the second type of agency problem between major shareholders and minority and medium shareholders. They pointed out that the shareholding structure of enterprises in many countries is not highly dispersed but there are several major shareholders. At this point, the major shareholder becomes an agent, who exercises the power of the entire company's shares to influence the company's decision-making in order to encroach on the interests of minority shareholders [10]. As the internal rights protection mechanism, internal control strengthens the information transmission within the enterprise, effectively guarantees the performance of the contract, reduces the misconduct of the enterprise, and thus produce protection effect of the minority shareholders [11] [12]. And the integrated management of internal control and external media supervision can reduce management agency costs and protect the interests of stakeholders more effectively [13]. Yang et al. (2009) found improving the quality of internal control helps to curb the two types of agent costs [14]. Lin et al. (2012) found the internal control of different property rights has different effects on different agency problems [15]. The root cause of the two types of agency problems is the inconsistency of the objective function between the principal and agent caused by information asymmetry and non-convergence of interests. Lv et al. (2008) pointed out that although the implementation subjects and specific methods of benefit encroachment may have different forms, the essence is that the interest groups who hold the residual control rights of the company seek to realize their own interests by exercising the residual control rights. In this sense, the core of restricting interest encroachment is to limit the abuse of residual control through a series of internal and external institutional arrangements [16]. Internal control is a kind of control arrangement and control mechanism, which can effectively guarantee the performance of the enterprise contract, make up for the incompleteness of the contract and lock the residual control right in the "cage". In addition, the internal control optimizes the interests of the principal and the agent by designing an effective incentive mechanism. It also alleviates the degree of information asymmetry and reduces the possibility of opportunistic accounting choices by supervising the reliability of financial accounting information. Therefore, this paper proposes hypotheses $2 \mathrm{a}, 2 \mathrm{~b}$.

H2a: when other conditions are the same, good internal controls can reduce the cost of the first type of agency.

$\mathrm{H} 2 \mathrm{~b}$ : when other conditions are the same, good internal controls can reduce the cost of the two types of agency.

\subsection{Internal Control, Dual Agency Cost and Corporate Social Responsibility}

Enterprises need to invest resources in fulfilling their social responsibilities. 
These inputs tend to be rewarded in the long run, and may even have a negative return on corporate performance in the short term [17], while the agent's interest interval is often short-term. The compensation of enterprise managers is often linked to the short-term performance of the company. When there is a serious agency conflict with the shareholders, the manager is likely to reduce the corresponding social responsibility expenditures to maintain the market competitiveness and business performance, even manipulate the accounting surplus and reduce information disclosure. When there is a serious agency conflict between the major shareholder and the minority shareholders, it will intensify the behavior of the major shareholder about invading the company's assets and harming the interests of the minority shareholders to pursue their own interests. At this time, the major shareholders will not pay attention to the overall needs of other stakeholders, resulting in low levels of CSR. They even cover up their behavior by reducing the disclosure of relevant information. Although the market supervision environment is becoming more stringent, the behavior of controlling shareholders may not be effectively constrained [18]. Internal control, as the most basic institutional arrangement in internal corporate governance and daily operations, infiltrates into every aspect of corporate life. Good internal control can constrain the behavior of managers and major shareholders, ease information asymmetry, strengthen the supervision of the principal on the agent, alleviate the two types of agency problems, and improve the fulfillment level of CSR. Li et al. (2019) concluded that internal control can alleviate the first type of agency conflict to promote corporate social responsibility [19]. Therefore, this paper proposes the hypotheses $3 \mathrm{a}, 3 \mathrm{~b}$.

H3a: When other conditions are the same, internal control promotes corporate social responsibility performance by reducing the cost of the first type of agency, that is, the first type of agency costs play a mediating role.

H3b: When other conditions are the same, internal control promotes corporate social responsibility performance by reducing the cost of the second type of agency, that is, the second type of agency costs play a mediating role.

\section{Data and Methodology}

\subsection{Sample Selection and Data Sources}

This paper takes the data of China's A-share non-financial listed companies from 2013 to 2017 as the research sample, and deletes the following listed companies according to the research needs: 1) ST companies; 2) Delisted companies; 3) Companies with missing financial data. At the same time, this article deletes other samples of missing data, and finally obtains 10,034 company annual data. In order to reduce the influence of outliers, this paper winsorizes the main continuous variables. The internal control data comes from Dibo's internal control index of China's listed companies. The CSR data comes from Hexun's CSR rating score. Other relevant data are from CSMAR database. This paper uses Excel 2016 and Stata 15 for data processing and regression analysis. 


\subsection{Variable Definition}

1) Interpreted variables-CSR

There are two main methods for measuring CSR in the existing research: First, analyze the dimensions of CSR and use the relevant data to build a CSR rating through calculation formulas [20]. Second, use the CSR rating of third-party professional organizations to measure the level of fulfillment of social responsibility. Based on the research method of Jia [21], this paper takes the CSR rating score published by HeXun.com as an index to evaluate the performance of CSR. The higher the overall score, the better the CSR performance.

\section{2) Explanatory variables-internal control}

Shenzhen Dibo's internal control and risk management database integrates the five elements of internal control to objectively evaluate the internal control of China's listed companies. In recent years, Dibo's internal control index of Chinese listed companies has been widely used in related research. Therefore, by referring to the research methods of Quan et al. [22], this paper takes Dibo's internal control index of Chinese listed companies as an index to evaluate the quality of internal control. The larger the value, the better the internal control quality.

\section{3) Intermediary variables-dual agency costs}

For the first type of agency cost, according to the calculation method of Ang [23] et al., the agency cost between managers and shareholders is measured by the ratio of management fees to operating income. The higher the ratio, the more serious the first type of proxy conflict.

For the second type of agency cost, the most common way for major shareholders to occupy the interests of minority shareholders is to occupy the funds of listed companies. Therefore, this paper draws on the practice of Wei et al. [24] to measure the agency cost between major shareholders and minority shareholders by the ratio of other receivables to total assets. The larger the ratio, the more serious the second type of proxy conflict.

\section{4) Control variables}

Based on the existing research, this paper selects the enterprise size, profitability, executive compensation, independent director ratio, financial leverage, enterprise growth, equity concentration, and nature of property as control variables. At the same time, this paper also controls the annual effect and industry effect. The specific definition and calculation method of all variables are shown in Table 1.

\subsection{Model Design}

In order to verify the hypothesis of this paper, the following model is constructed:

$$
\begin{aligned}
\mathrm{CSR}_{i, t} & =\alpha_{i}+\alpha_{1} \mathrm{IC}_{i, t}+\Sigma \mathrm{Conrtol}_{i, t}+\Sigma \text { Year }+\Sigma \mathrm{Ind}+\varepsilon_{i, t} \\
\mathrm{AC}_{i, t} & =\beta_{i}+\beta_{1} \mathrm{IC}_{i, t}+\Sigma \mathrm{Conrtol}_{i, t}+\Sigma \text { Year }+\Sigma \mathrm{Ind}+\varepsilon_{i, t}
\end{aligned}
$$




$$
\begin{gathered}
\mathrm{CSR}_{i, t}=\eta_{i}+\eta_{1} \mathrm{IC}_{i, t}+\eta_{2} \mathrm{ACl}_{i, t}+\Sigma \operatorname{Conrtol}_{i, t}+\Sigma \text { Year }+\Sigma \mathrm{Ind}+\varepsilon_{i, t} \\
\mathrm{AC}_{i, t}=\beta_{i}^{\prime}+\beta_{1}^{\prime} \mathrm{IC}_{i, t}+\Sigma \mathrm{Contol}_{i, t}+\Sigma \text { Year }+\Sigma \mathrm{Ind}+\varepsilon_{i, t} \\
\mathrm{CSR}_{i, t}=\eta_{i}^{\prime}+\eta_{1}^{\prime} \mathrm{IC}_{i, t}+\eta_{2}^{\prime} \mathrm{AC}_{i, t}+\Sigma \operatorname{Conrtol}_{i, t}+\Sigma \text { Year }+\Sigma \text { Ind }+\varepsilon_{i, t}
\end{gathered}
$$

\section{Results and Discussion}

\subsection{Descriptive Statistics}

Descriptive statistics of the study variables are shown in Table 2. From the table, the average value of CSR is 25.603 , the minimum value is -2.72 , the maximum value is 76.06 , and the standard deviation is 16.696 , indicating that the overall awareness of CSR performance in China is weak and the level of fulfillment is very different. The minimum value of internal control quality is 0 , indicating that some listed companies in China have major defects in internal control, while the maximum value is 809.190 , indicating that the actual governance effect of internal control has significant differences. The average of the two types of agency costs are 0.101 and 0.02 , indicating that the second type of agency conflict is significantly relieved under supervision and governance while the first type of agency problem is still serious. Moreover, the difference between the maximum and minimum value of the two types of agency costs is obvious, indi-

\begin{tabular}{|c|c|c|}
\hline Variable & Definition & Description \\
\hline CSR & Corporate social responsibility & the CSR rating score published by HeXun.com \\
\hline IC & Internal control & Dibo's internal control index of listed companies \\
\hline $\mathrm{AC} 1$ & First type of agency cost & the ratio of management fees to operating income \\
\hline $\mathrm{AC} 2$ & Second type of agency cost & the ratio of other receivables and total assets \\
\hline Size & enterprise size & The company's total assets take the natural logarithm \\
\hline Roa & Profitability & $\begin{array}{l}\text { the ratio of company's current year net profit to } \\
\text { year-end total assets }\end{array}$ \\
\hline Lnsal & Executive compensation & $\begin{array}{l}\text { the top three executives' compensation take the natural } \\
\text { logarithm }\end{array}$ \\
\hline Indep & Independent director ratio & The ratio of independent directors to all directors \\
\hline Lev & Financial leverage & The ratio of total liabilities to total assets \\
\hline Growth & Enterprise growth & $\begin{array}{l}\text { The ratio of current year operating income growth to } \\
\text { last year operating income }\end{array}$ \\
\hline Top3 & Equity concentration & $\begin{array}{l}\text { The sum of the shareholding ratio of the top three } \\
\text { shareholders }\end{array}$ \\
\hline State & Nature of property & $\begin{array}{l}\text { When the actual controller is a state-owned property } \\
\text { right, the variable is set to } 1 \text {; otherwise, it is set to } 0\end{array}$ \\
\hline Year & Annual effect & Five years, four annual dummy variables are generated \\
\hline Ind & Industry effect & $\begin{array}{l}\text { Generate industry dummy variables according to the } \\
\text { industry classification of China securities regulatory } \\
\text { commission in } 2012\end{array}$ \\
\hline
\end{tabular}
cating that some enterprises in China have very serious agency problems.

Table 1. Variable definitions and descriptions. 
Table 2. Descriptive statistics.

\begin{tabular}{ccccccc}
\hline Variables & $\mathrm{N}$ & Max & Min & Mean & Median & SD \\
\hline CSR & 10,034 & 76.060 & -2.720 & 25.603 & 22.030 & 16.696 \\
IC & 10,034 & 809.190 & 0.000 & 648.220 & 662.455 & 100.408 \\
AC1 & 10,034 & 0.459 & 0.002 & 0.101 & 0.084 & 0.078 \\
AC2 & 10,034 & 0.179 & 0.000 & 0.020 & 0.011 & 0.029 \\
Size & 10,034 & 28.509 & 18.219 & 22.315 & 22.150 & 1.293 \\
Lev & 10,034 & 1.280 & 0.008 & 0.432 & 0.422 & 0.206 \\
Roa & 10,034 & 0.590 & -0.646 & 0.039 & 0.033 & 0.051 \\
Indep & 10,034 & 0.800 & 0.182 & 0.374 & 0.333 & 0.056 \\
Growth & 10,034 & 251.211 & -0.926 & 0.332 & 0.109 & 3.422 \\
Top3 & 10,034 & 0.983 & 0.084 & 0.481 & 0.475 & 0.152 \\
State & 10,034 & 1.000 & 0.000 & 0.400 & 0.000 & 0.490 \\
Lnsal & 10,034 & 17.406 & 11.490 & 14.324 & 14.300 & 0.677 \\
\hline
\end{tabular}

\subsection{Correlation Analysis}

Table 3 shows the results of correlation analysis of variables. The correlation coefficient of the enterprise size and financial leverage is 0.525 , indicating that there may be multiple collinearity. After calculating the variance inflation factor, it is found that the mean value of variance inflation factor is 1.38 and the maximum value is 2.36 , which is much lower than 10 . Therefore, the possibility of severe multicollinearity among variables is basically ruled out. In addition, internal control and CSR are positively correlated at a significant level of $1 \%$, which preliminarily confirms hypothesis 1 . Internal control and two types of agency costs are both negatively correlated at a significant level of $1 \%$, preliminarily confirming hypothesis $2 \mathrm{a}$ and $2 \mathrm{~b}$. Two types of agency costs are negatively correlated with CSR at a significant level of $1 \%$, which preliminarily verifies the hypothesis of mediating effect in this paper.

\subsection{Regression Results and Discussion}

In this paper, the F-test, the likelihood ratio test and the Hausmann test are used to finally adopt the fixed effect model for regression. Moreover, considering the heteroscedasticity of long panel data, all regressions in this paper use robustness estimates and Table 4 shows the regression analysis results of each model. According to the results of model 1 , internal control and CSR are positively correlated at the level of $1 \%$ significance, indicating that the better the internal control quality, the higher the CSR performance level. Hypothesis 1 is verified. According to the results of models 2 and 4, internal control is negatively correlated with the two types of agency costs at the significance level of $1 \%$, indicating that good internal control can effectively suppress the two types of agency costs. Hypothe- 
sis $2 \mathrm{a}$ and $2 \mathrm{~b}$ are verified. This paper draws on the method of Wen et al. (2014) [25] to test the mediating effects of two types of agency costs. The first step is to test the coefficient $\alpha_{1}$ of model 1 , which is significantly not zero. The second step is to test the coefficient $\beta_{1}$ of the model 2 and the coefficient $\eta_{2}$ of the model 3, both of which are significantly not zero. In the third step, the coefficient $\eta_{1}$ of the model 3 is tested, which is also significantly not zero, and $\beta_{1} * \eta_{2}$ is the same symbol as $\eta_{1}$, indicating that the first type of agency cost plays a partial intermediary role in the relationship between internal control and CSR. The ratio of the mediating effect to the total effect is $\left(\beta_{1} * \eta_{2}\right) / \alpha_{1}$, which is about $4 \%$, hypothesis $3 \mathrm{a}$ is verified. We use the same method to verify whether the second type of agency costs have a mediating effect. Step one, $\alpha_{1}$ is not significantly zero. Step two, the coefficient $\beta_{1}^{\prime}$ of the model 4 is not significantly zero while the coefficient $\eta_{2}^{\prime}$ of the model 5 does not pass the significance test. Step three, the mediation effect of AC2 was tested with Bootstrap method, referring to Wen's original steps. The results are shown in Table 5. The mediating effect failed to pass the significance test and hypothesis $3 \mathrm{~b}$ failed to be verified.

\subsection{Robustness Test}

The robust estimation method is used for regression in this paper, which guarantees the reliability of the conclusion to a certain extent. In addition, this paper also performs logarithmization on the interpreted variable CSR and explanatory variable IC and uses the ROE and the first major shareholding ratio TOP1 as the surrogate indicators of profitability and equity concentration in the control variables. The results of regression (shown in Table 6) and mediating effect test are not substantially different from the above.

Table 3. Variable correlation analysis.

\begin{tabular}{|c|c|c|c|c|c|c|c|c|c|c|c|c|}
\hline & CSR & IC & $\mathrm{AC} 1$ & AC2 & SIZE & LEV & ROA & INDEP & GROW & TOP3 & STATE & LNSAL \\
\hline CSR & 1 & & & & & & & & & & & \\
\hline IC & $0.207^{\star * *}$ & 1 & & & & & & & & & & \\
\hline $\mathrm{AC} 1$ & $-0.162^{\star * *}$ & $-0.139^{\star * *}$ & 1 & & & & & & & & & \\
\hline AC2 & $-0.077^{\star * *}$ & $-0.139^{\star * *}$ & $0.071^{\star * *}$ & 1 & & & & & & & & \\
\hline Size & $0.287^{\star \star \star}$ & $0.159^{\star * *}$ & $-0.397^{* * *}$ & $-0.018^{\star}$ & 1 & & & & & & & \\
\hline Lev & 0.015 & $-0.023^{\star *}$ & $-0.349^{* * *}$ & $0.210^{\star * *}$ & $0.525^{\star * *}$ & 1 & & & & & & \\
\hline Roa & $0.346^{* * *}$ & $0.266^{* * *}$ & $-0.099^{* * *}$ & $-0.164^{\star \star *}$ & -0.003 & $-0.335^{\star * *}$ & 1 & & & & & \\
\hline Indep & -0.013 & 0.011 & $0.060^{\star * *}$ & 0.0140 & $0.017^{\star}$ & -0.01 & $-0.024^{\star \star}$ & 1 & & & & \\
\hline Growth & 0.003 & $0.030^{\star * *}$ & $-0.028^{* * *}$ & 0.005 & $0.029^{* * *}$ & $0.027^{\star * *}$ & $0.037^{\star * *}$ & 0.00700 & 1 & & & \\
\hline Top3 & $0.152^{\star * *}$ & $0.106^{* * *}$ & $-0.158^{* * *}$ & $-0.106^{* * *}$ & $0.259^{* * *}$ & $0.032^{\star * *}$ & $0.126^{\star * *}$ & $0.048^{\star * *}$ & $0.018^{*}$ & 1 & & \\
\hline State & $0.136^{\star * *}$ & $0.053^{* * *}$ & $-0.192^{* * *}$ & $0.038^{\star * *}$ & $0.354^{\star * *}$ & $0.291^{\star * *}$ & $-0.108^{* * *}$ & $-0.047^{* * *}$ & $-0.042^{* * *}$ & $0.136^{* * *}$ & 1 & \\
\hline Lnsal & $0.265^{\star * *}$ & $0.150^{\star * *}$ & $-0.098^{\star * *}$ & $-0.041^{\star * *}$ & $0.442^{\star * *}$ & $0.137^{* * *}$ & $0.204^{\star * *}$ & -0.012 & 0.008 & $0.092^{* * *}$ & $0.073^{* * *}$ & 1 \\
\hline
\end{tabular}

Note: Table 3 shows Pearson correlation analysis. *, ** and ${ }^{* * *}$ indicate significant at the levels of $10 \%, 5 \%$ and $1 \%$. 
Table 4. Regression results of each model.

\begin{tabular}{|c|c|c|c|c|c|}
\hline & model (1) & model (2) & model (3) & model (4) & model (5) \\
\hline & CSR & $\mathrm{AC} 1$ & CSR & $\mathrm{AC} 2$ & CSR \\
\hline \multirow[t]{2}{*}{ IC } & $0.00607^{\star * *}$ & $-0.0000208^{\star * *}$ & $0.00583^{* * *}$ & $-0.0000119^{* * *}$ & $0.00605^{* * *}$ \\
\hline & $(3.49)$ & $(-2.76)$ & $(3.37)$ & $(-3.77)$ & $(3.46)$ \\
\hline \multirow[t]{2}{*}{$\mathrm{AC} 1$} & & & $-11.67^{\star * *}$ & & \\
\hline & & & $(-3.45)$ & & \\
\hline \multirow[t]{2}{*}{$\mathrm{AC} 2$} & & & & & -2.147 \\
\hline & & & & & $(-0.33)$ \\
\hline \multirow[t]{2}{*}{ Size } & $3.622^{\star * *}$ & $-0.0163^{\star * *}$ & $3.432^{* * *}$ & $-0.00523^{\star * *}$ & $3.611^{\star * *}$ \\
\hline & $(8.90)$ & $(-5.04)$ & $(8.33)$ & $(-3.99)$ & $(8.83)$ \\
\hline \multirow[t]{2}{*}{ Lev } & -2.513 & $-0.0345^{\star * \star}$ & $-2.915^{*}$ & $0.0171^{* * *}$ & -2.476 \\
\hline & $(-1.60)$ & $(-3.04)$ & $(-1.85)$ & $(3.93)$ & $(-1.57)$ \\
\hline \multirow[t]{2}{*}{ Roa } & $77.07^{\star * *}$ & $-0.243^{\star * *}$ & $74.23^{\star * \star}$ & 0.00452 & $77.08^{\star \star *}$ \\
\hline & (13.89) & $(-10.04)$ & (12.98) & $(0.44)$ & $(13.89)$ \\
\hline \multirow[t]{2}{*}{ Indep } & 3.725 & -0.00200 & 3.701 & 0.000328 & 3.725 \\
\hline & $(0.87)$ & $(-0.14)$ & $(0.86)$ & $(0.05)$ & $(0.87)$ \\
\hline \multirow[t]{2}{*}{ Growth } & -0.00947 & $-0.000865^{\star}$ & -0.0196 & -0.000109 & -0.00971 \\
\hline & $(-0.28)$ & $(-1.78)$ & $(-0.58)$ & $(-0.86)$ & $(-0.29)$ \\
\hline \multirow[t]{2}{*}{ Top3 } & -2.486 & $-0.0261^{\star *}$ & -2.791 & $-0.0148^{\star *}$ & -2.518 \\
\hline & $(-1.09)$ & $(-2.18)$ & $(-1.23)$ & $(-2.39)$ & $(-1.10)$ \\
\hline \multirow[t]{2}{*}{ Lnsal } & $1.185^{\star \star}$ & $0.00650^{\star * *}$ & $1.261^{\star \star \star}$ & 0.000334 & $1.186^{\star *}$ \\
\hline & $(2.55)$ & $(2.91)$ & $(2.70)$ & $(0.35)$ & $(2.55)$ \\
\hline \multirow[t]{2}{*}{ State } & 1.614 & 0.00558 & 1.679 & 0.000948 & 1.616 \\
\hline & $(1.00)$ & $(0.40)$ & $(1.04)$ & $(0.22)$ & $(1.00)$ \\
\hline \multirow[t]{2}{*}{ Cons } & $-67.01^{\star * *}$ & $0.419^{\star * *}$ & $-62.13^{\star * *}$ & $0.152^{\star \star \star}$ & $-66.69^{\star \star *}$ \\
\hline & $(-6.98)$ & $(6.01)$ & $(-6.44)$ & $(5.01)$ & $(-6.92)$ \\
\hline Year & control & control & control & control & control \\
\hline Ind & control & control & control & control & control \\
\hline $\mathrm{N}$ & 10034 & 10034 & 10034 & 10034 & 10034 \\
\hline Adjusted $R^{2}$ & 0.197 & 0.139 & 0.198 & 0.026 & 0.197 \\
\hline
\end{tabular}

Note: ${ }^{*},{ }^{* *}$ and ${ }^{* * *}$ indicate significant at the levels of $10 \%, 5 \%$ and $1 \%$ and $t$-stats in parentheses, the same below.

Table 5. Bootstrap method mediation effect test results.

\begin{tabular}{ccccccc}
\hline & $\begin{array}{c}\text { Observed } \\
\text { Coef. }\end{array}$ & $\begin{array}{c}\text { Bootstrap } \\
\text { Std. Err. }\end{array}$ & $\mathrm{z}$ & $\mathrm{P}>|\mathrm{z}|$ & \multicolumn{2}{c}{$\begin{array}{c}\text { Normal-based } \\
\text { [95\% Conf. Interval] }\end{array}$} \\
\hline _bs_1(ind_eff) & 0.0000518 & 0.0001365 & 0.38 & 0.704 & -0.0002157 & 0.0003192 \\
_bs_2(dir_eff) & 0.0116238 & 0.0017548 & 6.62 & 0.000 & 0.0081844 & 0.0150632 \\
\hline
\end{tabular}


Table 6. Main regression results of robustness test.

\begin{tabular}{cccccc}
\hline & $(1)$ & $(2)$ & $(3)$ & $(4)$ & $(5)$ \\
\hline \multirow{2}{*}{ LNIC } & LNCSR & AC1 & LNCSR & AC2 & LNCSR \\
& $0.738^{* * *}$ & $-0.0384^{* * *}$ & $0.647^{* * *}$ & $-0.00655^{* *}$ & $0.739^{* * *}$ \\
& $(10.24)$ & $(-6.23)$ & $(9.06)$ & $(-2.43)$ & $(10.22)$ \\
AC1 & & & $-2.497^{* * *}$ & & \\
& & & $(-8.86)$ & & \\
AC2 & & & & & 0.0464 \\
& & & & & $0.12)$ \\
Cons & $-7.732^{* * *}$ & $0.757^{* * *}$ & $-5.966^{* * *}$ & $0.191^{* * *}$ & $-7.741^{* * *}$ \\
& $(-11.29)$ & $(8.72)$ & $(-8.57)$ & $(5.40)$ & $(-11.18)$ \\
N & 9708 & 9908 & 9708 & 9908 & 9708 \\
Adjusted $R^{2}$ & 0.124 & 0.084 & 0.145 & 0.027 & 0.124 \\
\hline
\end{tabular}

Note: since some values of IC and CSR are less than or equal to 0 , the sample number changes after taking logarithm.

\section{Research Conclusions and Recommendations}

This paper takes the relevant data of China's A-share non-financial listed companies from 2013 to 2017 as the research sample and studies the relationship and mechanism between internal control, dual agency costs and CSR. The research finds: 1) The internal control quality and social responsibility performance of Chinese enterprises are uneven and the overall awareness of social responsibility performance is relatively weak. 2) Internal control is significantly positively correlated with CSR, that is, good internal control can promote enterprises to fulfill social responsibility. 3) Internal control is significantly negatively correlated with the cost of both types of agency, that is, good internal control can effectively suppress the agency costs between managers and shareholders as well as major shareholders and minority shareholders. 4) The first type of agency cost plays a partial intermediary role in the relationship between internal control and CSR, that is, effective internal control promotes CSR performance by mitigating the first type of agency conflict, while the second type of agency costs does not play an intermediary role.

Based on the above conclusions, this paper proposes the following: 1) Relevant regulatory authorities should strengthen the construction of laws and regulations for internal control, improve the evaluation system of third-party institutions, increase the supervision and disclosure of corporate social responsibility, establish a complete reward and punishment system and improve the overall awareness of corporate social responsibility performance. The external supervision mechanism of enterprises which can effectively protect the interests of stakeholders should be guided to supervise internal control and CSR. 2) Enterprises should avoid the negative attitude that fulfilling the social responsibility is to cope with external supervision, actively integrate CSR into corporate values 
and development strategies, build a sound and effective internal control system and implement them in a practical manner. The formulation and implementation departments of internal control should pay attention to the protection of the rights and interests of all stakeholders and timely stop the misconduct of major shareholders and management. Enterprises would attach importance to the principal-agent problem, and give play to the positive role of good internal control in the governance of the two types of agency problems. That can improve the comprehensive governance level of enterprises. The appeals of interest parties and the environmental impact of enterprises can not be ignored; these are important components of corporate social responsibility.

\section{Conflicts of Interest}

The author declares no conflicts of interest regarding the publication of this paper.

\section{References}

[1] Davis, K. (1960) Can Business Afford to Ignore Social Responsibilities? California Management Review, 2, 70-76. https://doi.org/10.2307/41166246

[2] Sheldon, O. (1930) The Philosophy of Management. Sir I. Pitman and Sons. https://doi.org/10.4324/9780203507827

[3] Zhang, L.T. and Wang, J.L. (2016) Does Internal Control Quality Influence Corporate Social Responsibility Level. Journal of Northwest University (Philosophy and Social Sciences Edition), 46, 55-62.

[4] Ling, Z.G., Zhang, C.Y. and Ding, M.H. (2018) Market Process, Internal Control Deficiencies and Restoration, and Corporate Social Responsibility. Journal of Anhui Normal University, 46, 57-68.

[5] Li, W. and Teng, Y. (2015) Research on the Relationship between Corporate Social Responsibility and Internal Control Effectiveness. Research on Financial and Economic Issues, 8, 105-109.

[6] Wang, H.B., Liu, S. and Han, B. (2015) The Effect of Internal Control and Financial Performance on Corporate Social Responsibility-An Empirical Analysis Based on Listed Companies of A-Share. Taxation and Economy, 6, 1-9.

[7] Li, Z.B. (2014) Internal Control, Nature of Actual Controller and Corporate Social Responsibility-Empirical Evidence from Chinese Listed Companies. Economic Survey, 31, 109-114.

[8] Li, W.Y. and Xiao, H.J. (2011) Logics for Corporate Social Responsibility. China Industrial Economics, 10, 87-97.

[9] Michael, C.J. and William, H.M. (1976) Theory of the Firm: Managerial Behavior, Agency Costs and Ownership Structure. Journal of Financial Economics, 3, 305-360. https://doi.org/10.1016/0304-405X(76)90026-X

[10] La Porta, R., Florencio, L. and Shleifer, A. (1999) Corporate Ownership around the World. Journal of Finance, 54, 471-518. https://doi.org/10.1111/0022-1082.00115

[11] Qin, J.P. (2017) The Effect of Protection on Small and Medium Stockholders' Interests in Internal Control of Mixed-Ownership Enterprises. China Business and Market, 31, 80-91.

[12] Liu, H., Xu, N. and Shi, S.H. (2015) The Role of "Double-Edged Sword" in Internal 
Control-Based on Budget Execution and Budget Relaxation. Management World, 12, 130-145.

[13] Peng, T.Y. and Ji, D.Y. (2014) Media Supervision, Quality of Internal Control and Agency Cost. The Theory and Practice of Finance and Economics, 35, 61-65.

[14] Yang, D.M., Lin, B. and Wang, Y.C. (2009) Internal Control, Audit Quality and Agency Cost. Journal of Finance and Economics, 35, 40-49+60.

[15] Lin, B., Lin, D.J., Hu, W.M., Yang, X. and Liu, S.M. (2012) Internal Control, Nature of Property Right, Agency Costs: Evidence from the 2001-2010 A-Share Listed Companies. China Accounting Association 2012 Academic Annual Meeting, Kunming, 7-8 July 2012, 1846-1856.

[16] Lv, C.J. and Xiao, C.M. (2008) Legal Environment, Corporate Governance and Expropriation: Evidence from the Comparison of Chinese and U.S. Stock Markets. China Accounting Review, 2, 141-162.

[17] Wen, S.B. and Fang, Y. (2008) An Empirical Research on Relationship between Corporate Social Responsibility and Financial Performance-Analysis Based on Stakeholder Theory and Panel Dates. China Industrial Economics, 10, 150-160.

[18] He, J.G., Sun, Z. and Li, Z.Q. (2010) Irrepressible Controlling Shareholder Behavior: Theoretical Explanation and Case Analysis. Accounting Research, 3, 20-27.

[19] Li, L.Y., Wang, Z.H. and Kan, L.N. (2019) Internal Control and Corporate Social Responsibility Performance: Mediating Effect Test Based on Agency Cost. Journal of Nanjing Audit University, 16, 28-36.

[20] Shen, H.T. (2005) A Study on the Relationship between Corporate Social Responsibility and Corporate Financial Performance under the Framework of Stakeholder Theory. PhD Thesis, Xiamen University, Xiamen.

[21] Jia, X.P. and Liu, Y. (2014) External Environment, Internal Resource, and Corporate Social Responsibility. Nankai Business Review, 17, 13-18+52.

[22] Quan, X.F., Wu, S.N. and Yin (2015) Corporate Social Responsibility and Stock Price Crash Risk: Self-Interest Tool or Value Strategy? Economic Research Journal, 50, 49-64.

[23] Ang, J., Cole, R. and Lin, J. (2000) Agency Costs and Ownership Structure. Journal of Finance, 55, 81-106. https://doi.org/10.1111/0022-1082.00201

[24] Wei, Z.H., Wu, Y.H. and Li, C.Q. (2012) Family Control, Double Principal-Agent Conflict and Cash Dividend Policy-An Empirical Study Based on Chinese Listed Companies. Journal of Financial Research, 7, 168-181.

[25] Wen, Z.L. and Ye, B.J. (2014) Analyses of Mediating Effects: The Development of Methods and Models. Advances in Psychological Science, 22, 731-745. https://doi.org/10.3724/SP.J.1042.2014.00731 